Article

\title{
Characterisation Method of the Passivation Mechanisms during the pre-discharge Stage of Plasma Electrolytic Oxidation Indicating the Mode of Action of Fluorides in PEO of Magnesium
}

\author{
Frank Simchen ${ }^{1, *(D)}$, Maximilian Sieber ${ }^{2}$, Thomas Mehner ${ }^{1}$ and Thomas Lampke ${ }^{2}$ (D) \\ 1 Materials and Surface Engineering Group, Chemnitz University of Technology, \\ D-09107 Chemnitz, Germany; thomas.mehner@mb.tu-chemnitz.de \\ 2 Department of Corrosion Protection and Testing, EXCOR Korrosionsforschung GmbH, \\ Magdeburger Straße 58, 01067 Dresden, Germany; maximilian.sieber@excor.de (M.S.); \\ thomas.lampke@mb.tu-chemnitz.de (T.L.) \\ * Correspondence: Frank.Simchen@mb.tu-chemnitz.de
}

Received: 16 September 2020; Accepted: 3 October 2020; Published: 10 October 2020

\begin{abstract}
Plasma electrolytic oxidation (PEO) is a method to obtain protective coatings on metallic light-weight construction materials. Here, the workpiece receives a strong anodic polarisation in a suitable aqueous electrolyte, which leads to the formation of a passive layer and a gaseous shell. Afterwards, plasma electrolytic discharges appear on the substrate surface and convert it into a ceramic layer. The properties of the passive layer are influenced by the selected substrate/electrolyte combination and are essential for the PEO process-initiation and characteristics. In this work, a new method for the systematic investigation of the substrate/electrolyte interactions during the pre-discharge stage is presented. The procedure is carried out by a polarisation experiment and allows for a quantitative characterisation of the passivation behavior, based on a small electrolyte volume. The method is used to investigate a literature-known electrical conduction mechanism on passive films formed on magnesium, by cross-comparison between different $\mathrm{Mg}$ and $\mathrm{Al}$ materials. In addition, the influence of phosphate, glycerol, and fluoride on the passivation behaviour of the Mg alloy AZ31 in an alkaline environment is considered and quantified. The results provide an explanatory approach for the positive influence of toxic fluorides within the electrolyte on the morphology of PEO layers on magnesium.
\end{abstract}

Keywords: plasma electrolytic oxidation; aluminium; magnesium; passivation; fluoride

\section{Introduction}

\subsection{Plasma Electrolytic Oxidation}

Plasma electrolytic oxidation (PEO) is a promising method for the surface treatment of metallic light-weight construction materials, such as aluminium, magnesium, titanium, and their alloys [1,2]. The workpiece is immersed within an aqueous electrolyte and receives a strong anodic polarisation. This procedure leads to the ionization of metal atoms at the substrate surface. These ions react with electrolyte constituents by the formation of insoluble, electrical isolating compounds and forming dense anodic barrier layer. In the context of PEO treatment, the process is called passivation. This so-called passive layer has a high electrical resistance, which causes a localized potential drop at the electrolyte/substrate-interface and a rising electrical field strength within the mentioned system. These conditions allow for layer growth by migration of substrate ions through the existing layer 
towards the electrolyte-side transition zone. Furthermore, a limited electronic charge transfer is made possible, which leads to the evolution of molecular oxygen by electrolysis of water [1].

The released oxygen forms a gas or rather a gas/steam shell close to the passive layer enveloping the substrate geometry. The interface between this gaseous shell and the bulk electrolyte is assumed to be an area of equal electrical potential following the topography of the anodically polarised metal. This so-called quasi-cathode becomes the point of origin for the plasma-chemical gas/solid reactions. Starting from the electrolyte, spark discharges strike through the gaseous shell and passive layer into the substrate. The discharges leave oxidised spots on the metal surface and convert it into a dense, protective oxide-ceramic layer, as long as appropriate process parameters are chosen. To prevent the transition from short-lasting, layer-forming spark discharges to long-lasting layer-deteriorating arc-discharges, $\mathrm{PEO}$ is usually carried out by alternating pulse patterns [3].

The model presented above shows that the passivation characteristics of a selected electrolyte/substrate system are essential for the PEO initiation, as well as for the progress of the entire process. Therefore, appropriate methods for the systematic investigation of these characteristics are necessary for the development of PEO processes for new materials and material combinations. Hence, in the present study, a new procedure for the characterisation of the passivation behaviour of substrate/electrolyte combination within the pre-discharge stage is proposed.

\subsection{Experimental Investigation of Passivation}

Up until now, passivation properties of a given system have qualitatively been classified according to Kurze [4,5] in substrate dissolution (I-II), passivation (V-VI), and various intermediates (III-IV) by means of current-density potential curves (Figure 1a).
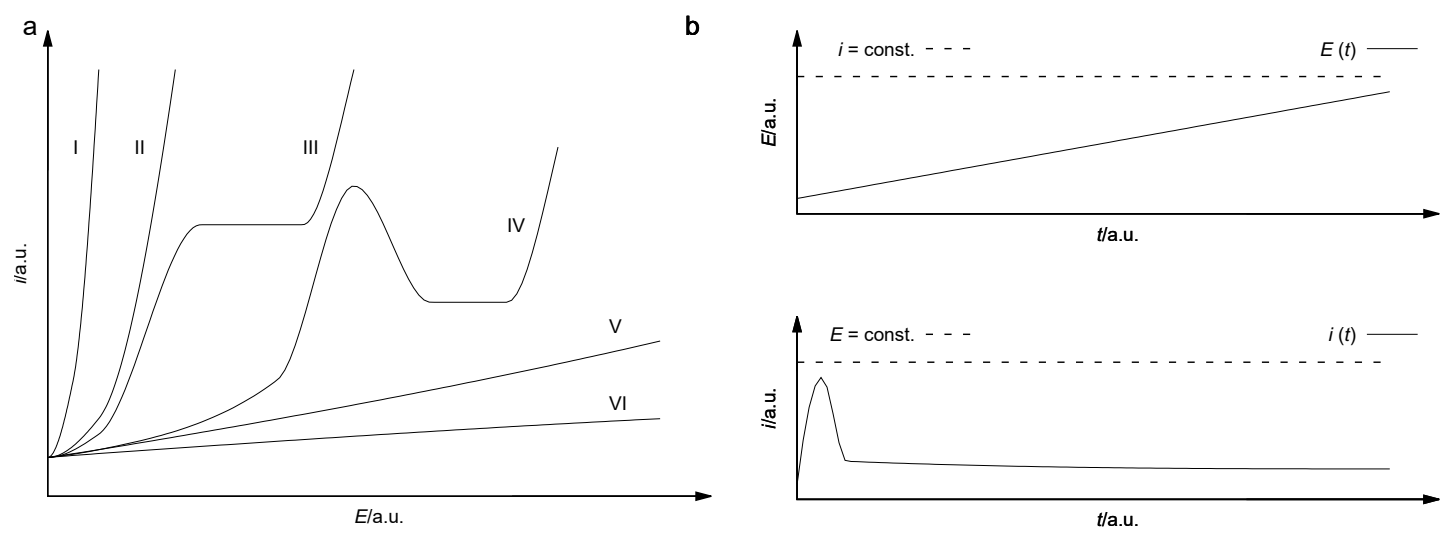

c

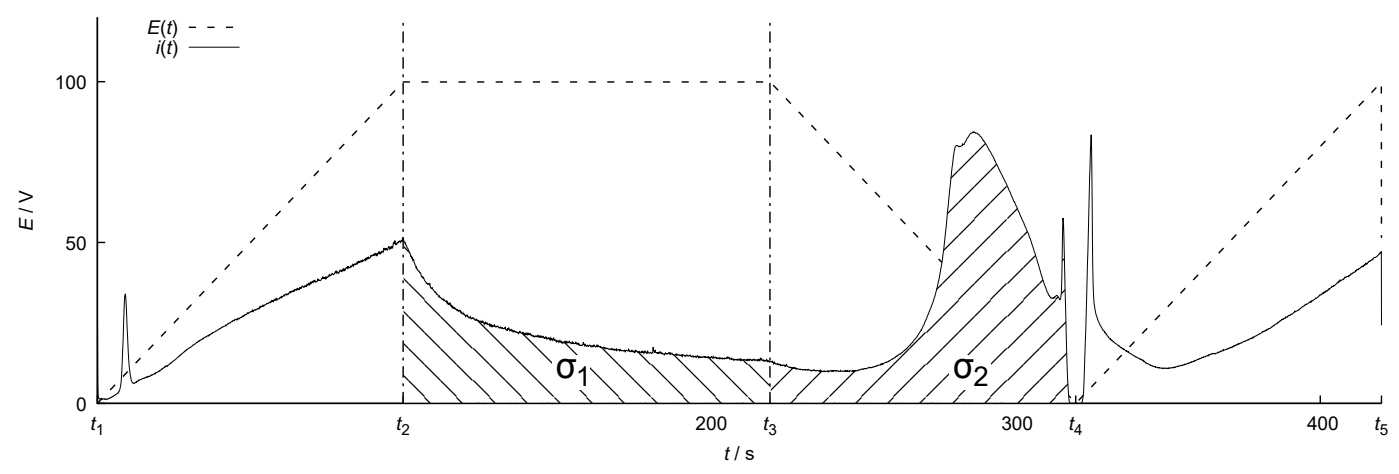

Figure 1. Comparative schematic representation of the results of qualitative polarisation $[4,5](\mathbf{a})$ and step measurements [6,7] (b) experiments as well as quantitative polarisation experiments (c) to determine the passivation capability of plasma electrolytic oxidation (PEO) electrolytes. 
Snizhko et al., on the other hand, use chronopotentiometric and chronoamperometric step measurements to investigate passivation processes on $\mathrm{Al}$ and $\mathrm{Mg}$ materials. For these measurements, the electrical reference variable is suddenly applied to the examined system and the resulting process variable is recorded [6,7] (Figure 1b). For the method presented in this study, defined potential cycles are imposed on the investigated system and the resulting current is integrated over specific time ranges (Figure 1c). This allows a quantitative assessment of the passivation behaviour, characterised by the amount of charge passed through the system $\left(\sigma_{1}\right)$ after the potential rise. Low values of $\sigma_{1}$ represent a passive surface state at the chosen potential, while high values of $\sigma_{1}$ indicate a high charge transfer and hence active surface state, in most cases due to dissolution of the substrate. In addition, the procedure facilitates the systematic investigation of an electrical conduction effect, which occurs on $\mathrm{Mg}$ substrates on formed passive films in the range of 40-1 V [8] and is quantified by the amount of charge passed in the phase of voltage decrease in the cycle $\left(\sigma_{2}\right)$. The procedure is orientated to the potential course of cyclic voltammetry. Due to the high maximum potentials and potential feeds, the test scenario is approximated to the conditions during the PEO process. Thus, the method represents a transitional form between the current-density/potential-measurements of Kurze, and Snizhko's step experiments.

\subsection{Electrolyte Constituents}

The PEO of magnesium materials is usually carried out in alkaline or weakly alkaline media. Glycerol [9-11] and phosphates [11,12] are named in the literature as electrolyte constituents.

Despite its toxicological concern, fluoride compounds are ingredients of various commercial electrolytes $[13,14]$. Numerous publications prove their positive influence on the morphology and corrosion protection properties of the resulting layers [15-19]. The work of Kazanski [20] and Moon [21] suggests that the addition of fluoride into the electrolyte suppresses the formation of a defect-rich zone between the substrate and the PEO layer, which is described by several authors for the PEO of $\mathrm{Mg}$ materials over a wide parameter range [11,20-24]. Figure 2 shows a schematic representation of the often described layer morphology obtained by PEO on aluminium materials (left) and on magnesium materials (right) within fluoride-free electrolytes.

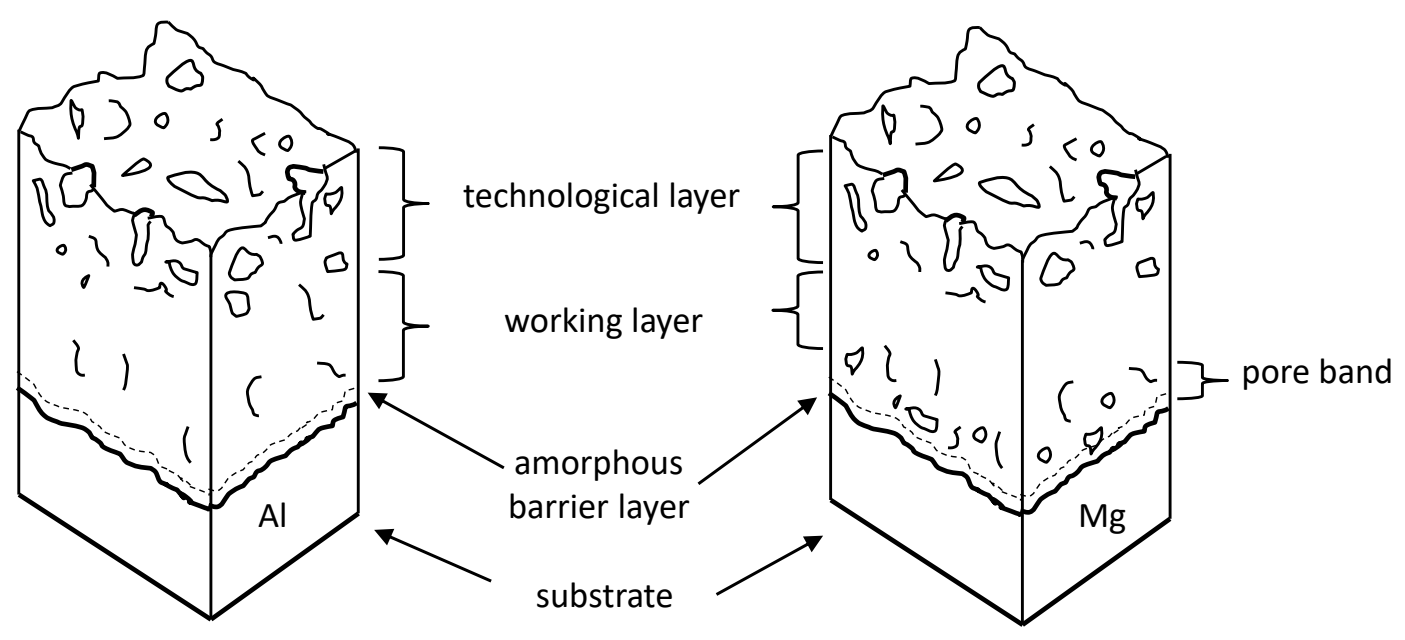

Figure 2. Schematic representation of the morphology of PEO layers on aluminium $[25,26]$ (left) and magnesium materials within fluoride-free electrolyte [23,24] (right).

The appearance of this zone, referred to by $\mathrm{Lu}$ and $\mathrm{Ma}$ as the pore band $[23,24]$, inevitably has a limiting effect on the technological layer properties such as wear and corrosion resistance and substrate adhesion.

The positive contribution of glycerol, phosphate and especially fluoride within the electrolyte could either originate from improved passivation or more complex interactions during the PEO 
process. Therefore, it is the aim of this study to use the method presented to investigate the influence of the above-mentioned electrolyte constituents on the passivation behaviour of the magnesium alloy AZ31. Furthermore, certain peculiarities in the passivation of $\mathrm{Mg}$ materials will be investigated by cross-comparison to aluminium substrates. Explanations for the observations made and a categorisation of the underlying passivation mechanisms are then proposed.

\section{Experimental Procedure}

\subsection{Setup, Methods, and Materials}

The experiments were carried out within a rotationally symmetric electrochemical cell. A 3-mol/l- $\mathrm{Ag} / \mathrm{AgCl}$-electrode serves as the reference (RE) and a platinum sheet as the counter electrode (CE). To minimise the influence of gas bubbles possibly formed at the sample surface, the working electrode (WE) is localised at the button of the cell. The active sample area has a diameter of $10 \mathrm{~mm}$. Holes in the cell lid allow a view of the sample during the measurement. The electrolyte volume is $250 \mathrm{~mL}$. Figure 3 shows a schematic representation of the cell arrangement.

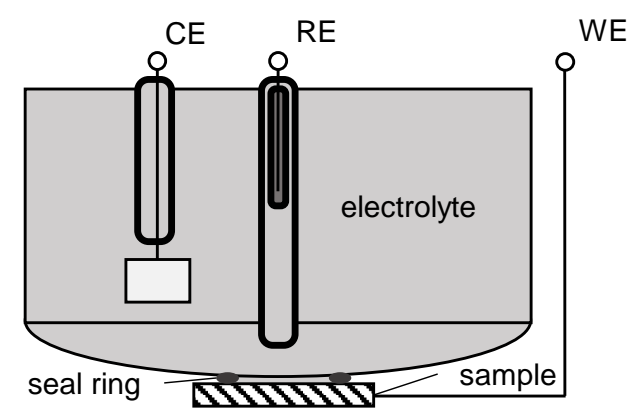

Figure 3. Schematic representation of the used cell arrangement.

The electrical regimes are applied by an electrochemical workstation Zennium connected with a potential booster CVB120 (both from Zahner elektrik, Germany). The vertices of the potential cycles described in Figure 1c are listed in Table 1.

Table 1. Vertices of the potential cycle used.

\begin{tabular}{lcccccc}
\hline $\boldsymbol{n}$ & 1 & 2 & 3 & 4 & 5 & 6 \\
\hline $\boldsymbol{E}_{\boldsymbol{n}} / \mathrm{V}$ & 0 & 100 & 100 & 0 & 100 & 0 \\
$\boldsymbol{t}_{n} / \mathrm{s}$ & 0 & 100 & 220 & 320 & 420 & $\approx 420$ \\
\hline
\end{tabular}

The characteristic values $\sigma_{1}$ and $\sigma_{2}$ are obtained by integration of the area-related current over the time period between $t_{2}$ and $t_{3}$ or $t_{3}$ and $t_{4}$, respectively:

$$
\begin{aligned}
& \sigma_{1}=\int_{t_{2}}^{t_{3}} i(t) \mathrm{d} t \\
& \sigma_{2}=\int_{t_{3}}^{t_{4}} i(t) \mathrm{d} t
\end{aligned}
$$

To ensure that a varied $\sigma$-value can clearly be attributed to an improved passivation, the electrolyte conductivities were measured with a laboratory multi-parameter system LM 2000 with a LVC $0.35 / 23$ electrode conductivity cell (Meinsberg, Germany) at $24^{\circ} \mathrm{C}$. To provide the data with statistical coverage, the polarisation measurements were carried out three times. Some measurements were evaluated using 
an analysis of variance. For this purpose, experiments were repeated five times each. The chemical compositions of the materials used are listed in Table 2.

Table 2. Chemical compositions of the materials used.

\begin{tabular}{lcccc}
\hline & \multicolumn{4}{c}{ Mass Fraction/\% } \\
Element & A1 99.5 & AlMgSi1 & Pure Mg & AZ31 \\
\hline $\mathrm{Al}$ & balance & balance & 0 & 3 \\
$\mathrm{Mg}$ & 0 & 1 & $\geq 99.9$ & balance \\
$\mathrm{Si}$ & $\leq 0.25$ & $0.7-1.3$ & 0 & 0 \\
$\mathrm{Zn}$ & 0 & 0 & 0 & 1 \\
\hline
\end{tabular}

To ensure comparable initial states of the test samples, they were pretreated by grinding on $4000 \mathrm{~cm}^{-2}$ paper, pickling, and subsequent rinsing under deionized water. The $\mathrm{Mg}$ materials were etched in 1:1 nitric acid at room temperature, and the Al materials in $30 \mathrm{~g} / \mathrm{L} \mathrm{NaOH}$ solution at $50{ }^{\circ} \mathrm{C}$. The electrolytes were prepared by analytically pure chemicals (Merck, Germany).

\subsection{Test Series}

Firstly, polarisation experiments were carried out in a solution consisting of $5 \mathrm{~g} / \mathrm{L} \mathrm{Na}_{2} \mathrm{SiO}_{3} \cdot 5 \mathrm{H}_{2} \mathrm{O}$ and $5 \mathrm{~g} / \mathrm{L} \mathrm{KOH}$ on the $\mathrm{Al}$ alloy AlMgSi1. From previous studies, it is known that this substrate/electrolyte combination is suitable for the formation of very compact and protective PEO layers $[25,26]$. Therefore, this procedure allows a technologically well-matched process to assign a $\sigma_{1}$-value, which can subsequently be used as a reference. In addition, it becomes possible to investigate whether the electrical conduction effect described for passive films formed on Mg-AZ31 under various conditions [8] also occurs on aluminium materials. In order to allow cross-comparisons and to exclude the possibly adulterating influence of alloying elements, the experiments were also carried out on the materials $\mathrm{Al}$ 99.5, Mg-AZ31, and technically pure $\mathrm{Mg}$ subsequently.

To investigate the electrical conduction effect, indicated by characteristic current-density peaks between $t_{3}$ and $t_{5}$, that was observed during the experiments on magnesium materials, further measurements were carried out. Therefore, the experimental procedure was repeated on Mg-AZ31 and pure $\mathrm{Mg}$ in pure $\mathrm{KOH}$-solution at $\mathrm{pH}=13$ without additional electrolyte constituents. This makes it possible to investigate the observed mechanism more precisely and to exclude interactions of electrolyte and alloy components as its origin.

As the current peaks were still obviously detectable, the next experiments were carried out on Mg-AZ31 in pure $\mathrm{KOH}$-solution at $\mathrm{pH}=13$ under adjusted potential cycles. The potential retraction from $U_{3}=100 \mathrm{~V}$ after $t_{3}=220 \mathrm{~s}$ with a potential feed of $1 \mathrm{~V} / \mathrm{s}$ was stopped at various end potentials $U_{\mathrm{e}}$, which were then kept constant until the end of the experiment at $t_{5}=420 \mathrm{~s}$. For the end potentials, different values $U_{\mathrm{e}} / \mathrm{V}=50,30,10,7,4.7$ were chosen. The observed occurrences could be interpreted in context of the so-called negative difference effect (NDE), which is known at magnesium electrodes for low positive potentials [27-29]. This NDE is combined by counterintuitive anodic hydrogen formation. Therefore, further such experiments were carried out with $U_{\mathrm{e}}=4.7 \mathrm{~V}$ and a significant prolonged testing time of $15 \mathrm{~min}$. The evolved gas was collected pneumatically and examined qualitatively by an oxyhydrogen test.

Another test series was carried out to investigate the influence of selected electrolyte constituents and their concentration on the passivation (quantified by $\sigma_{1}$ ) and the electrical conduction mechanism (quantified by $\sigma_{2}$ ) on Mg-AZ31 substrates. The electrolyte components were $\mathrm{C}_{3} \mathrm{H}_{5}(\mathrm{OH})_{3}, \mathrm{Na}_{2} \mathrm{HPO}_{4}$, and $\mathrm{NaF}$. The concentration levels were $0.03 \mathrm{~mol} / \mathrm{L}$ and $0.1 \mathrm{~mol} / \mathrm{L}$. To ensure comparability, the $\mathrm{pH}$ level was adjusted by $10 \mathrm{~g} / \mathrm{L} \mathrm{KOH}$ solution up to a value of 13 (see Table 3). The results of these experiments were evaluated by the use of an analysis of variance (ANOVA). 


\section{Results}

The results of the measurements within the electrolyte tested for the PEO of Al-AlMgSi1 on various $\mathrm{Al}$ and $\mathrm{Mg}$ materials are shown in Figure 4.

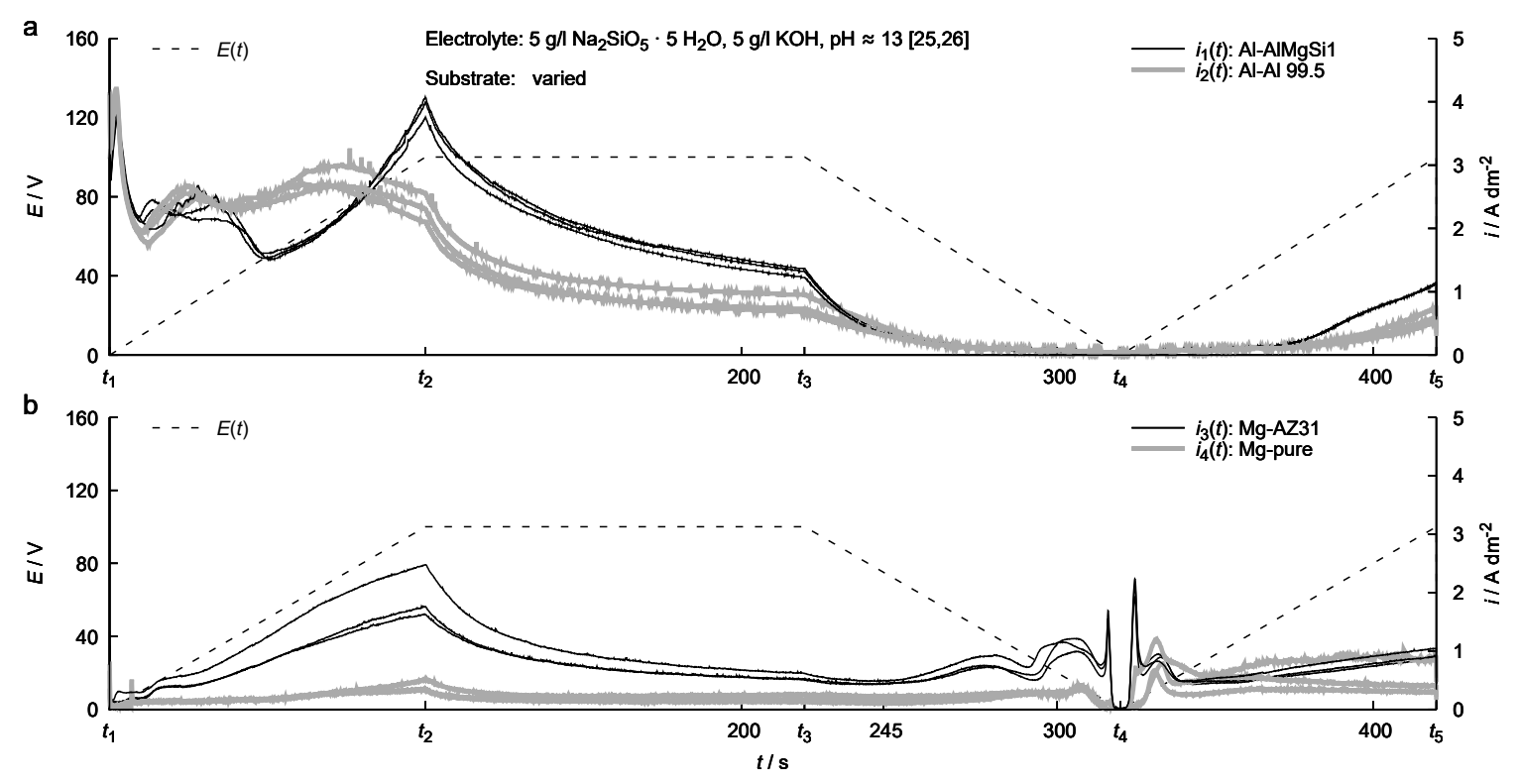

Figure 4. Results of polarisation experiments within an electrolyte which allows for the formation of dense and protective PEO layers on AlMgSi1 [25,26] on various $\mathrm{Al}(\mathbf{a})$ and $\mathrm{Mg}(\mathbf{b})$ materials the curves for three repetitions of each measurement are shown.

The current-density courses on the aluminium materials depicted in Figure 4a show a significant initial active peak. While the potential rises up to $100 \mathrm{~V}$, there are reproducible fluctuations in the $i(t)$ curve detectable. This behaviour can be attributed to the competition of simultaneous anodic processes taking place on the bare metal surface. They can allow the occurrence of current by metal dissolution and oxygen evolution or hinder it through passive film formation. During the following potential plateau between $t_{2}$ and $t_{3}$, the current flow lowers approximately exponentially. Over the following descending and rising potential ramps between $t_{3}$ and $t_{5}$, a likewise approximately exponential $i / U$ and $i / t$ correlation can be observed. In general, the current in this range is lower than during the initial fluctuations. This suggests that, between $t_{2}$ and $t_{4}$, the anodic processes are dominated by passive layer growth, which eases up at a constant potential because of the increasing layer thickness and varies in dependence of the potential, which is its driving force.

On the magnesium materials (Figure $4 \mathrm{~b}$ ), there are hardly any fluctuations detectable in the $i(t)$ curves during the initial potential ramp. While the potential is constant between $t_{2}$ and $t_{3}$, the current-density course is qualitatively similar to those on the aluminium materials. However, the current between $t_{1}$ and $t_{3}$ is in general significantly lower. This suggests that the process of passive film formation in the chosen electrolyte is much more dominant on the magnesium materials. However, in range of the sloping potential ramp, the literature-known electric conduction effect becomes detectable. At approximately $75 \mathrm{~V}(t=245 \mathrm{~s})$, the initially decreasing current-density profiles show a local minimum and then rise again. Afterwards, clearly visible current-density peaks occur, which are accompanied by intense gas evolution at the sample surface and its change of colour from transparent to dark grey. At the beginning of the subsequent rising potential ramp between $t_{3}$ and $t_{4}$, similar observations can be made. After a potential level of 20-30 V was reached, the peaks subsided. Subsequently, increases in current-density follow the potential course until the end of the experiment. During this period, no further gas evolution is visible. The colour of the sample surface turns from dark to a light grey.

The observations described allow the assumption that, during the electrical conduction effect, 
oxygen evolution and possibly also metal dissolution dominate the anodic processes, which have a destructive effect on the morphology of the passive film and significantly reduces its electrical resistance. The mechanism would thus have a depassivating character. Hence, the current course during the rising potential ramp between $t_{4}$ and $t_{5}$ could be interpreted as an active peak on the damaged passive film with subsequent repassivation.

Figure 5 shows a comparison of the $\sigma$-values extracted of the measurements in Figure 4.

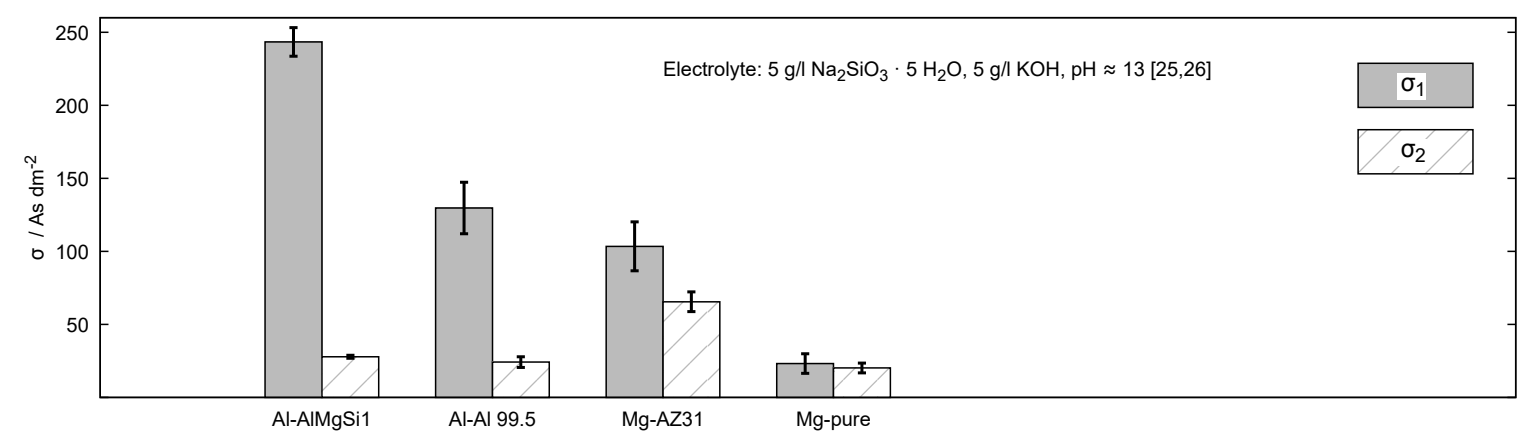

Figure 5. Comparison of the $\sigma$-values of the measurements shown in Figure 4.

The charge carrier throughput quantified by $\sigma_{1}$ is lower on magnesium than on aluminium materials. Hence, the Mg substrates show a better passivation under the selected conditions. Furthermore, the technical pure materials show a better passivation behaviour than the alloys. This suggests that the absence of substrate inhomogeneities supports the formation of a homogeneous, insulating passive layer.

The $\sigma_{2}$ obtained by the integration of the current between $t_{3}$ and $t_{4}$ is significantly higher on Mg-AZ31 than on the almunium materials. This is due to the described current-density peaks, which are presumably attributable to a depassivation mechanism. In contrast to the Al substrates, they are also present on pure magnesium. However, they are too low to be visible in this quantitative bar graph by an increased $\sigma_{2}$-value. This is in accordance with the assumption that the passive films formed on pure materials are more stable.

The results of the measurements on Mg-AZ31 and pure magnesium in $\mathrm{KOH}$-solution are depicted in Figure 6.

The current-density fluctuations during the rising $\left(t_{1}-t_{2}\right)$ and declining $\left(t_{3}-t_{4}\right)$ potential ramps are much more pronounced than during the measurements represented in Figure $4 \mathrm{~b}$. The current-density peaks between $t_{3}$ and $t_{4}$ are associated with intense gas evolution on both materials. In the case of the pure magnesium, the measurement data show transient current peaks and potential drops during the initial potential ramp. This is also accompanied by extensive gas evolution; discharge phenomena which could explain this behaviour [30] are not visible even in darkened experimental conditions. Furthermore, the measurements were terminated by the experimental setup at a process time of $t \approx 330$ s because the current limit was exceeded.

The observations made can be explained when compared to the measurements shown in Figure 4, in that the absence of silicate ions within the electrolyte results in the formation of less stable passive films. In the case of pure magnesium, this leads to time-limited layer breakthroughs accompanied by anodic gas evolution, even during the initial potential ramp. The experimental setup governs in the range of latency to a potential limitation, which allows a repassivation. However, the passive film damage occurring in the time domain between $t_{3}$ and $t_{4}$ is so strong that repassivation during the subsequent potential ramp under the given conditions is not possible.

The results of the measurements with adjusted potential cycle and varied end potential $U_{\mathrm{e}}$ on $\mathrm{Mg}-\mathrm{AZ} 31$ in $\mathrm{KOH}$ solution at $\mathrm{pH}=13$ are depicted in Figure 7. 

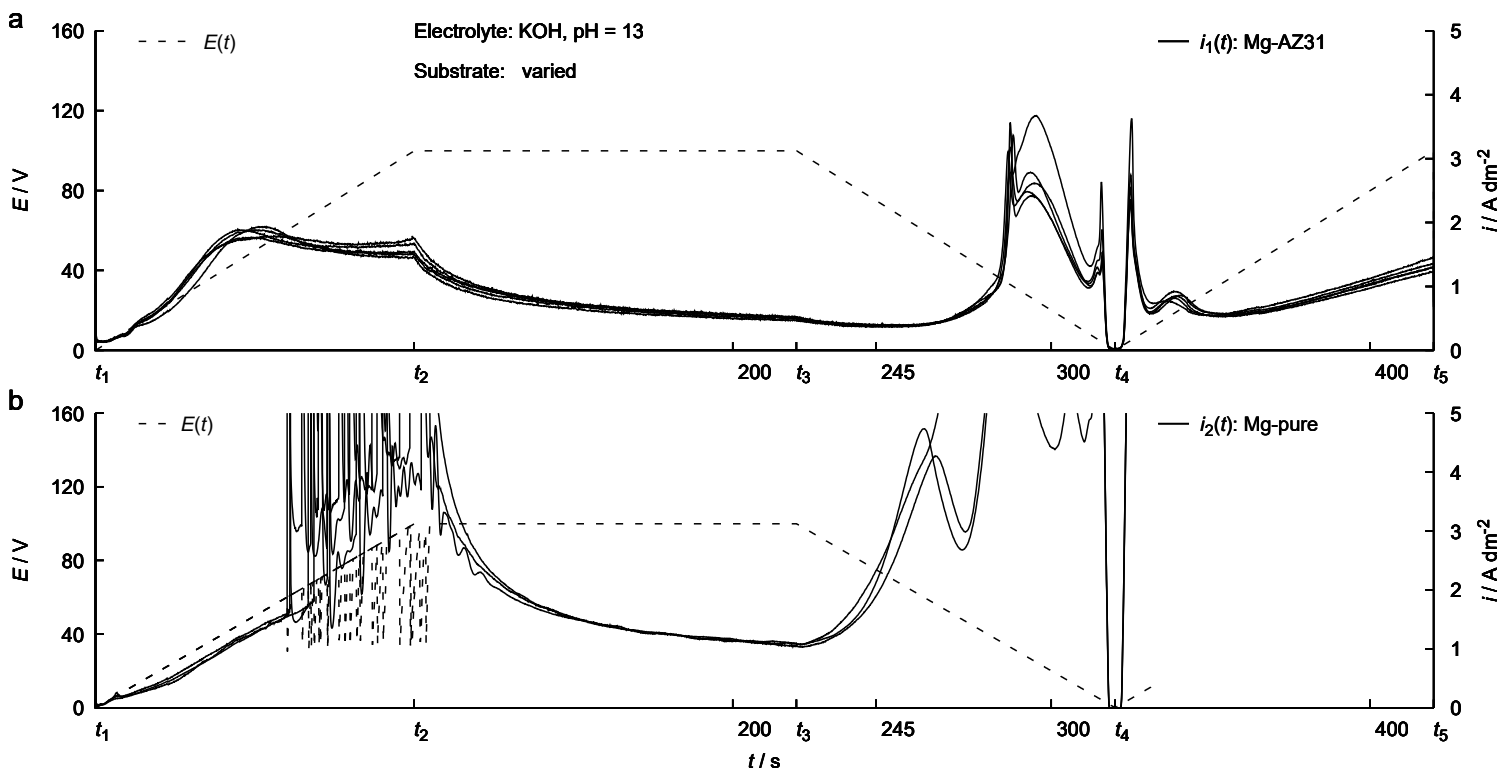

Figure 6. Results of polarisation experiments within $\mathrm{KOH}$ solution of $\mathrm{pH}=13$ on $\mathrm{Mg}-\mathrm{AZ} 31$ (a) and technical pure magnesium (b), the curves for several repetitions of each measurement are shown.

a

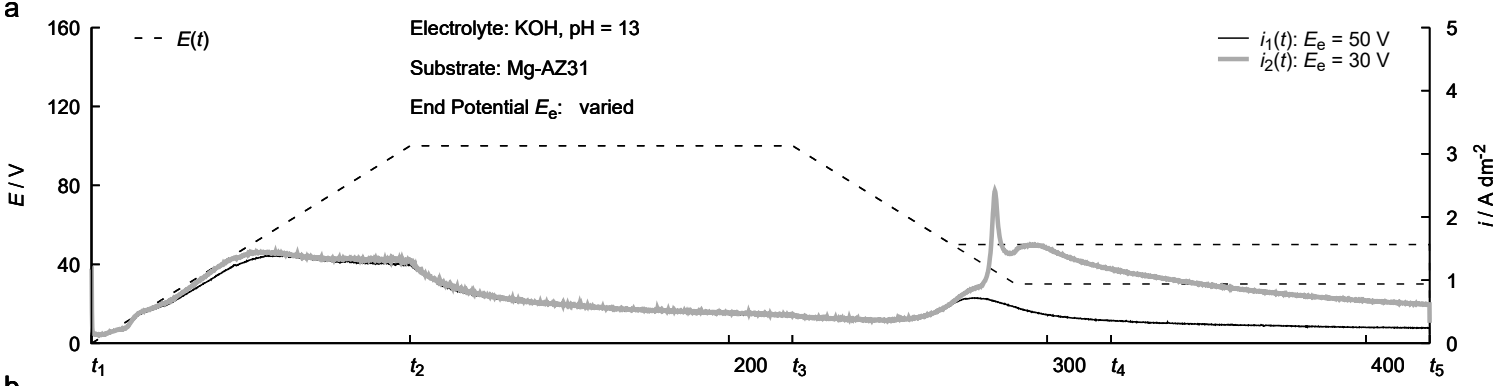

b

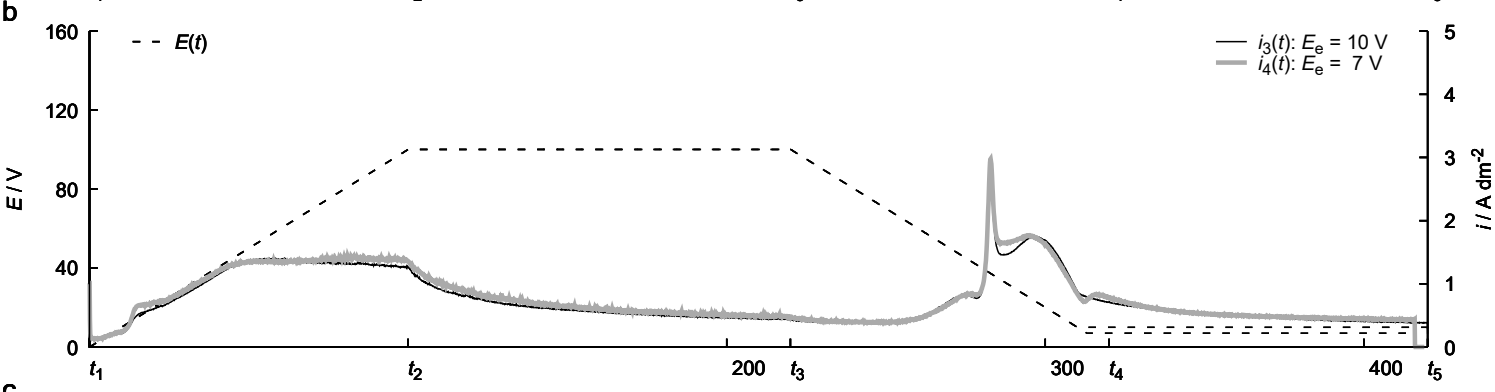

c

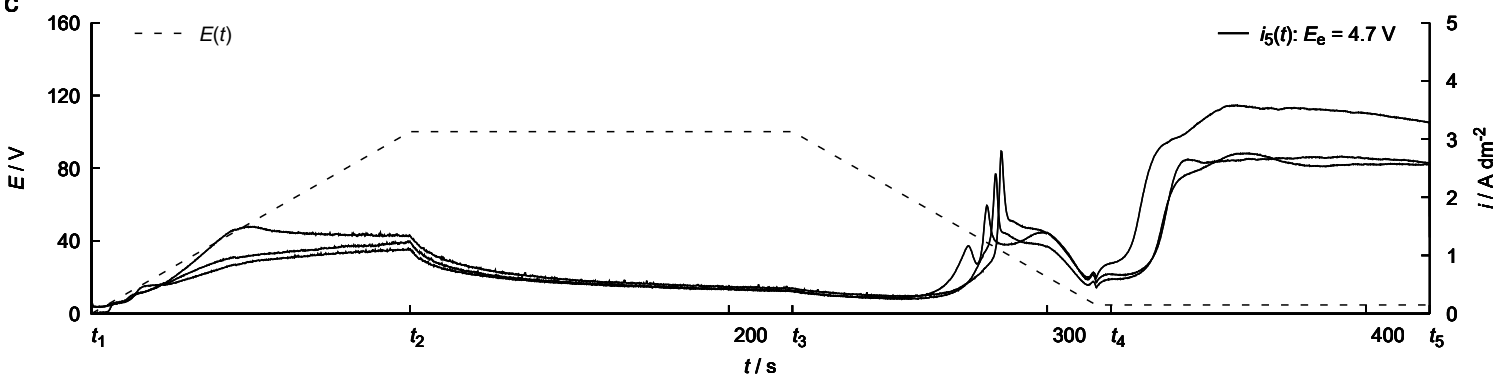

Figure 7. Results of polarisation experiments within $\mathrm{KOH}$ solution of $\mathrm{pH}=13$ on $\mathrm{AZ31}$ with different end potentials $U_{\mathrm{e}}$, for $U \mathrm{e}=4.7 \mathrm{~V}$ the curves for three repetitions of the measurement are shown.

All $i(t)$ curves show an initial active peak, followed by current-density fluctuations during the first potential ramp. Furthermore, the current-density courses show an approximately exponential time dependence during the subsequent potential plateau. This behaviour is known from the experiments presented in Figure 6a and underlines their reproducibility. 
However, the expression of the depassivating peaks in the rage of the declining potential ramp after $t_{3}$ varies significantly in dependence of the end potential. While at $U_{\mathrm{e}}=50 \mathrm{~V}$, only a shallow $i(t)$-peak is observed, the measurements with $U_{\mathrm{e}}=30-7 \mathrm{~V}$ show extensive current-density peaks, which are accompanied by intense gas evolution and a darkening of the passive film. At $U_{\mathrm{e}}=4.7 \mathrm{~V}$, on the other hand, after strong current-density fluctuations, a high current accompanied by gas evolution persists. The sample surface becomes dark grey. These observations suggest that critical potential ranges exist around $U_{\mathrm{e}}=4.7 \mathrm{~V}$, where the anodic reactions on formed magnesium passive films are outweighed by metal dissolution and gas evolution compared to passive film formation. Thus, potential courses throughout this range lead to passive film damage and staying at the critical point to passive film destruction.

The oxyhydrogen tests of the pneumatically-collected gas did not show any flames or sound emission. It can therefore be assumed that no significant amount of hydrogen has been developed. However, it should be taken into account that the experiments showed that a very low amount of anodic gas formation occurs during the entire polarisation experiment before the characteristic current-density peaks.

The result of the experiments regarding the influence of selected electrolyte constituents and their concentration on the passivation behaviour of Mg-AZ31 substrates are depicted in Figure 8.

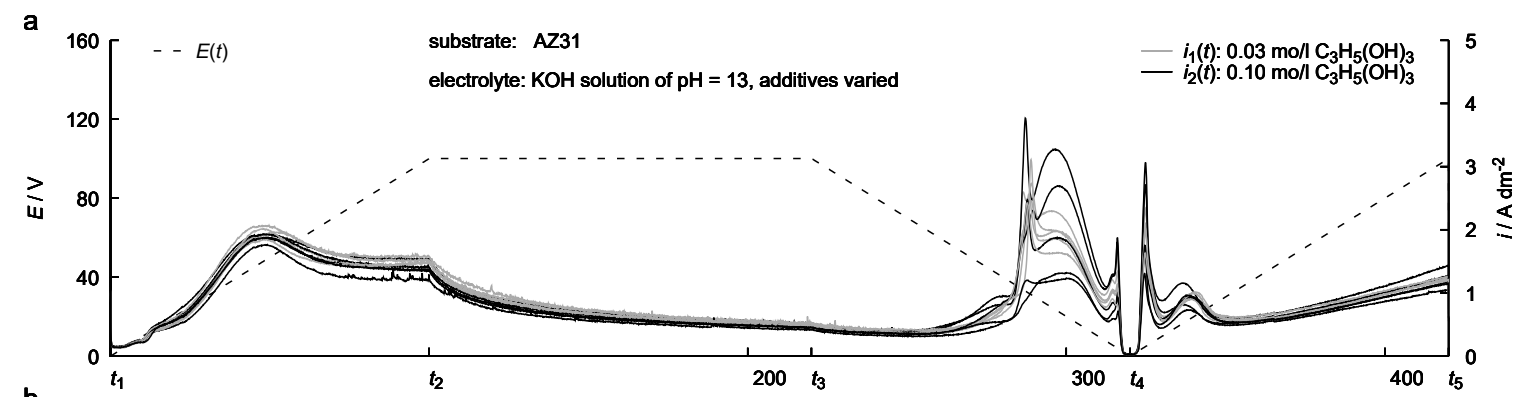

b

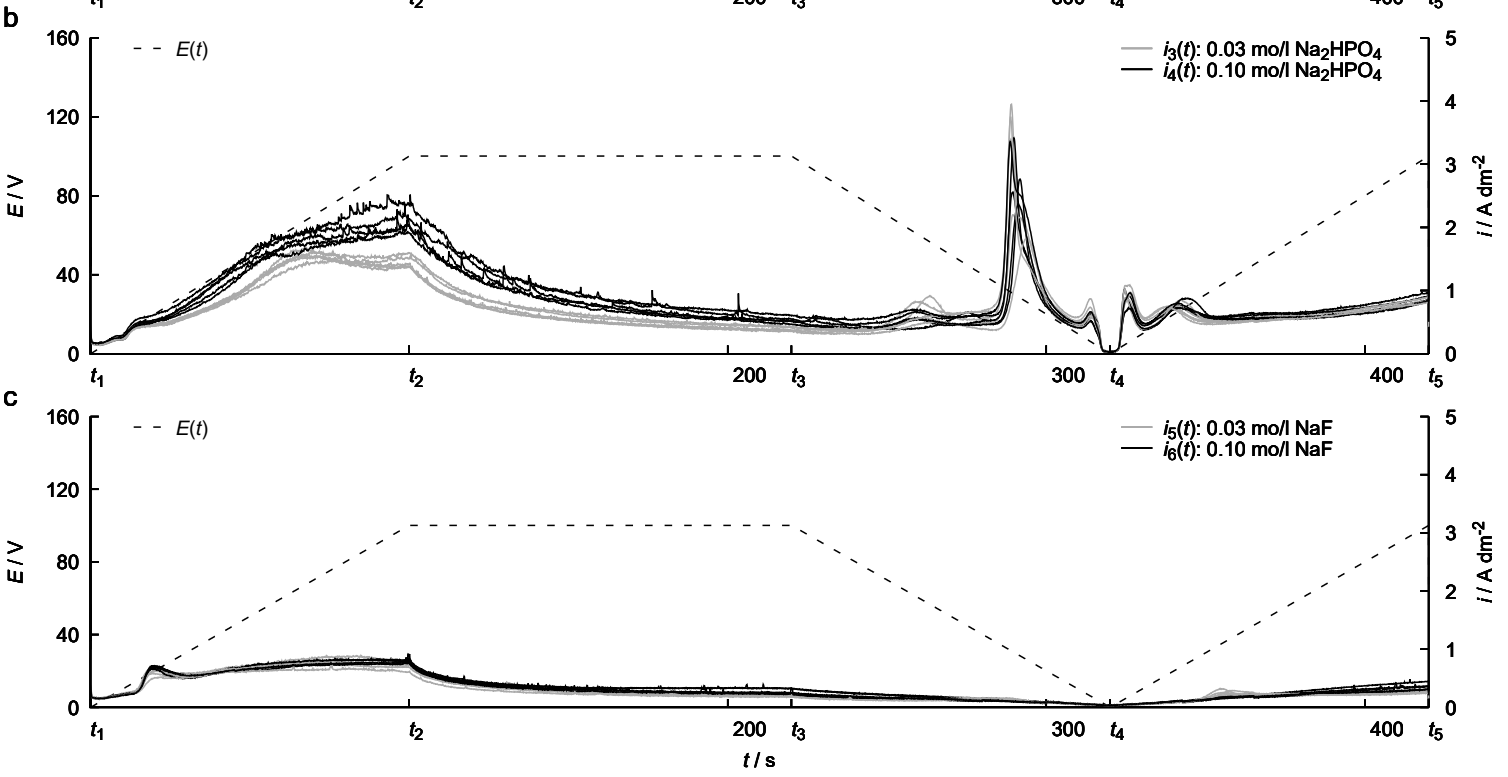

Figure 8. Results of polarisation experiments within $\mathrm{KOH}$ solution of $\mathrm{pH}=13$ with various electrolyte additives, the curves for five repetitions of each measurement are shown.

Table 3 lists the electrical conductivities of the electrolytes used. 
Table 3. Chemical composition, and conductivity $\kappa_{\mathrm{el}}$ of the electrolytes for the experiments depicted in Figure 8; the $\mathrm{pH}$ of the electrolytes was adjusted by the addition of $\mathrm{KOH}$ solution up to $\mathrm{pH}=13$.

\begin{tabular}{lcc}
\hline Substance & $\boldsymbol{c} / \mathbf{m o l} \cdot \mathbf{1}^{\mathbf{- 1}}$ & $\boldsymbol{\kappa}_{\mathrm{el}} / \mathbf{m S} \cdot \mathbf{c m}^{\mathbf{- 1}}$ \\
\hline $\mathrm{Na}_{2} \mathrm{HPO}_{4}$ & 0.03 & 36.1 \\
& 0.10 & 53.5 \\
$\mathrm{C}_{3} \mathrm{H}_{5}(\mathrm{OH})_{3}$ & 0.03 & 20.3 \\
(glycerol) & 0.10 & 21.9 \\
$\mathrm{NaF}$ & 0.03 & 20.9 \\
& 0.10 & 26.8 \\
\hline
\end{tabular}

For all solutions, the electrical conductivity is in the range of several tens of $\mathrm{mS} / \mathrm{cm}$, and hence high enough, that the potential drop over the electrolyte can be neglected. Hence, variations of the current courses depicted in Figure 8 can be attributed clearly to shifted passive layer properties. Figure 9 summarises the $\sigma$-values of the measurements presented in Figure 8.

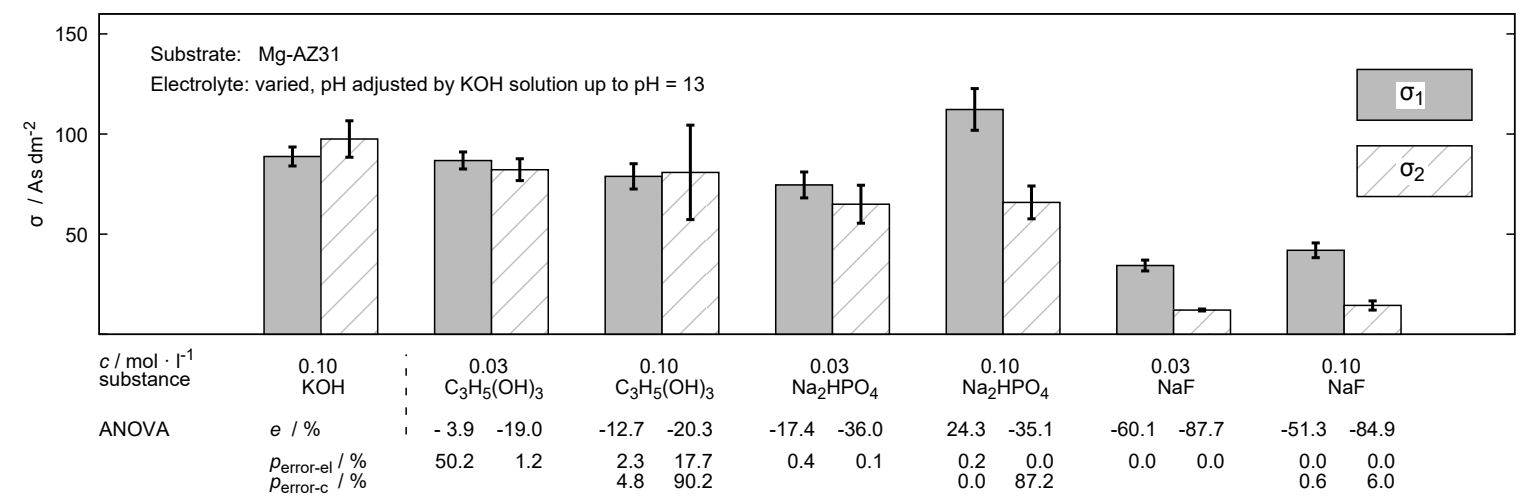

Figure 9. Comparison of the $\sigma$-values of the measurements shown in Figures $6 \mathrm{a}$ and 8 , as well as the percentage effect size $e$ of the different electrolyte variations and the error probability $p_{\text {error }}$ assuming the effect of an certain electrolyte component and the elevation of its concentration as statistically significant.

These experiments are identical to those depicted in Figure 6a, in terms of experimental set up, procedure, substrate, and electrolyte alkalinity. Therefore, the corresponding $\sigma$-values have been added to the bar graph as a reference for the influence of the studied electrolyte variations. Furthermore, the diagram contains the percentage effect size $e$ of the electrolyte variations, as well as the results of the ANOVA given by the error probability, assuming that the effect of a certain electrolyte component ( $\left.p_{\text {error-el }}\right)$ compared to the pure $\mathrm{KOH}$ electrolyte and the elevation of its concentration $\left(p_{\text {error-c }}\right)$ is statistically significant. Effects with a probability of error of less than $5 \%$ are assumed to be statistically significant. The $i(t)$ courses shown in Figure 8a,b for measurements in glycerol- and phosphate-added electrolytes are qualitatively similar to those in pure $\mathrm{KOH}$ solution depicted in Figure 6a. Glycerol additions influence the current-density peaks that occur between $t_{3}$ and $t_{4}$. However, the strong spread of the curves does not initially allow a clear classification of this effect. Within the phosphate electrolytes, an initially reduced current can be observed during the initial potential ramp between $t_{1}$ and $t_{2}$, and in addition, the characteristic current-density peaks are narrower and occur partially offset in time. Furthermore, the $i(t)$ curves show a slightly transient behaviour between $t_{1}$ and $t_{3}$ for the 0.1 molar phosphate solution. In contrast, fluoride additives lead to completely different experimental results. The current-density is lowered significantly over the entire measurements and does not exceed $0.5 \mathrm{~A} / \mathrm{dm}^{2} . i(t)$ - fluctuations during the initial potential ramp are hardly detectable and vanish between $t_{3}$ and $t_{4}$.

With the exception of the 0.1 molar phosphate solution, all investigated electrolyte additives achieved an improved passivation compared to pure $\mathrm{KOH}$ solution. For glycerol, this effect is 
only statistically significant for $\sigma_{2}$ at a concentration of $0.03 \mathrm{~mol} / \mathrm{L}$ and for $\sigma_{1}$ at a concentration of $0.1 \mathrm{~mol} / \mathrm{L}$. With an increase in concentration from 0.03 to $0.1 \mathrm{~mol} / \mathrm{L}$, the phosphate additives lead to a deteriorated passivation (quantified by $\sigma_{1}$ ), while the $\sigma_{2}$-value is not influenced to a statistically significant extent. The fluoride solution leads to a significant reduction in both passivation values at a 0.03 molar concentration, but a statistically significant increase can be observed for $\sigma_{1}$ when the concentration is increased to $0.1 \mathrm{~mol} / \mathrm{L}$. The characteristic current-density peaks vanish completely for both concentration levels.

In general, the measurements presented in this study were very sensitive to sample pretreatment. Preliminary tests (not shown here) with rougher samples show qualitatively similar $i(t)$ curves with noticeably higher currents. In the case of the experiment described in Figure $7 \mathrm{c}$, keeping $U_{\mathrm{e}}$ at $4.7 \mathrm{~V}$ resulted in current-densities of over $9 \mathrm{~A} / \mathrm{dm}^{2}$. Here, the passive film was completely destroyed, while deep black voluminous reaction products formed. The latter were easy to rinse off after the experiment, leaving a shallow depression on the sample exposure area.

The observations described can be explained by the increased roughness leading to an enlarged active sample surface. Electrochemically formed passive films only have a thickness of several tens of $\mathrm{nm}$. Hence, the measurements are very sensitive to the sample topography.

\section{Discussion}

The results depicted in the Figures 4 and 5 indicate that the passivation quantified by $\sigma_{1}$ is not a limiting factor for the PEO of magnesium. The achievable values are significantly below the level which is sufficient to form compact PEO layers on aluminium. However, it was clearly shown that the processes between $t_{3}$ and $t_{4}$ quantified by $\sigma_{2}$ occur exclusively on $\mathrm{Mg}$ materials. The current-density peaks within the alkaline silicate electrolyte were significantly lower on technically pure magnesium than on Mg-AZ31. In pure potassium hydroxide solution, however, the effect on technically pure magnesium was more pronounced than on Mg-AZ31, as can be seen in Figure 6. Thus, it becomes clear that the underlying processes are influenced by electrolyte and alloy components, but are an intrinsic property of magnesium passive films in alkaline environments.

The experiments summarised in Figure 7 showed that the increased current persists if the potential is kept constant at a specific value of $U_{\mathrm{e}}=4.7 \mathrm{~V}$. The additional current-density peaks at around $42 \mathrm{~V}$ and $28 \mathrm{~V}$ suggest that there could be at least two additional such characteristic potential values in the system under consideration. The intense gas evolution and dark discolouration of the passive film during the increased current indicate that non-passive layer-forming anodic processes such as oxygen formation and metal dissolution dominate. The process observed would therefore have a depassivating character. Respecting the fact that plasma electrolytic oxidation is usually carried out with alternating pulse patterns, this mechanism could occur several ten or hundred times every second during PEO of magnesium, depending on the chosen frequency.

This could be the reason for elevated porosity ate the substrate/layer interface of PEO coatings on magnesium depicted in Figure 2. This theory is supported by the fact that recent studies show, by TEM micrographs, small cavities within the amorphous barrier film of PEO layers formed on $\mathrm{Mg}$ in flouride free electrolytes [31].

Hereafter, a model is proposed to interpret the processes described, which is then used to explain the influences of individual electrolyte components summarised in Figures 8 and 9.

The appearance of the characteristic current-density peaks could be explained as follows. Under anodic polarisation, the following reactions compete with each other on magnesium samples in alkaline environment at the substrate/electrolyte interface:

- formation of magnesium hydroxide:

$$
\begin{aligned}
\mathrm{Mg} & \rightarrow \mathrm{Mg}^{2+}+2 \mathrm{e}^{-} \\
\mathrm{Mg}^{2+}+2 \mathrm{OH}^{-} & \rightarrow \mathrm{Mg}(\mathrm{OH})_{2}
\end{aligned}
$$


- dissociation of water molecules and hydroxide ions:

$$
\begin{aligned}
2 \mathrm{H}_{2} \mathrm{O} & \rightarrow 4 \mathrm{H}^{+}+\mathrm{O}_{2}+4 \mathrm{e}^{-} \\
2 \mathrm{OH}^{-} & \rightarrow 2 \mathrm{H}^{+}+\mathrm{O}_{2}+4 \mathrm{e}^{-}
\end{aligned}
$$

According to the corresponding Pourbaix diagram, reactions (3) and (4) are favoured thermodynamically on blank magnesium surfaces within alkaline media. During the most time of the polarisation measurements, the applied potential is over the decomposition potential of water. Hence, reactions (3) and (4), as well as (5) and (6), are possible thermodynamically.

Before the current-density peaks occur $\left(t_{1}-t_{3}\right)$, only a very low gas evolution can be observed. This proves that reactions (3) and (4) dominate at first, the $\mathrm{Mg}(\mathrm{OH})_{2}$ film largely blocks the flow of electrons, but still has a low residual electron conductivity, which enables reactions (5) and (6) to a limited extent. Maintaining $\mathrm{Mg}(\mathrm{OH})_{2}$ formation requires migration of the ions involved through the continuously growing passive film. Therefore, the activation energy of the reaction increases with increasing passive film thickness. Keeping the potential (and thus the available activation energy) constant $\left(t_{2}-t_{3}\right)$ leads to a decreased reaction rate. If the potential is subsequently decreased, the level of the energy previously required to activate the reaction is undercut $\left(t_{3}-t_{4}\right)$. The $\mathrm{Mg}(\mathrm{OH})_{2}$ formation temporarily subsides and reactions (5) and (6) become more dominant. This is accompanied by an elevated current and a visible gas evolution, which is interpreted as oxygen formation. According to reactions (5) and (6), additional protons are released, which lead to local $\mathrm{pH}$ reduction of the electrolyte and cause damage to the passive film (according to Figure 10, magnesium hydroxide is only stable in an high alkaline environment). As the protons drift towards the cathode and the locally thinned passive film allows magnesium hydroxide to form again, repassivation takes place for the moment. This process is repeated several times along the falling potential ramp and explains the occurrence of the current-density fluctuation. At $U_{\mathrm{e}}=4.7 \mathrm{~V}$, the equilibrium finally shifts in favour of reaction (5) and (6). When the potential is reduced further, the electrochemical charge flow ultimately comes to a standstill.

The experiments on aluminium depicted in Figure 4 did not show this behaviour, hence the formed $\mathrm{Al}_{2} \mathrm{O}_{3}$ (whose stability range was expanded to alkaline by the silicate additives) has a high electrical resistance and is stable in neutral media, see Figure 10.
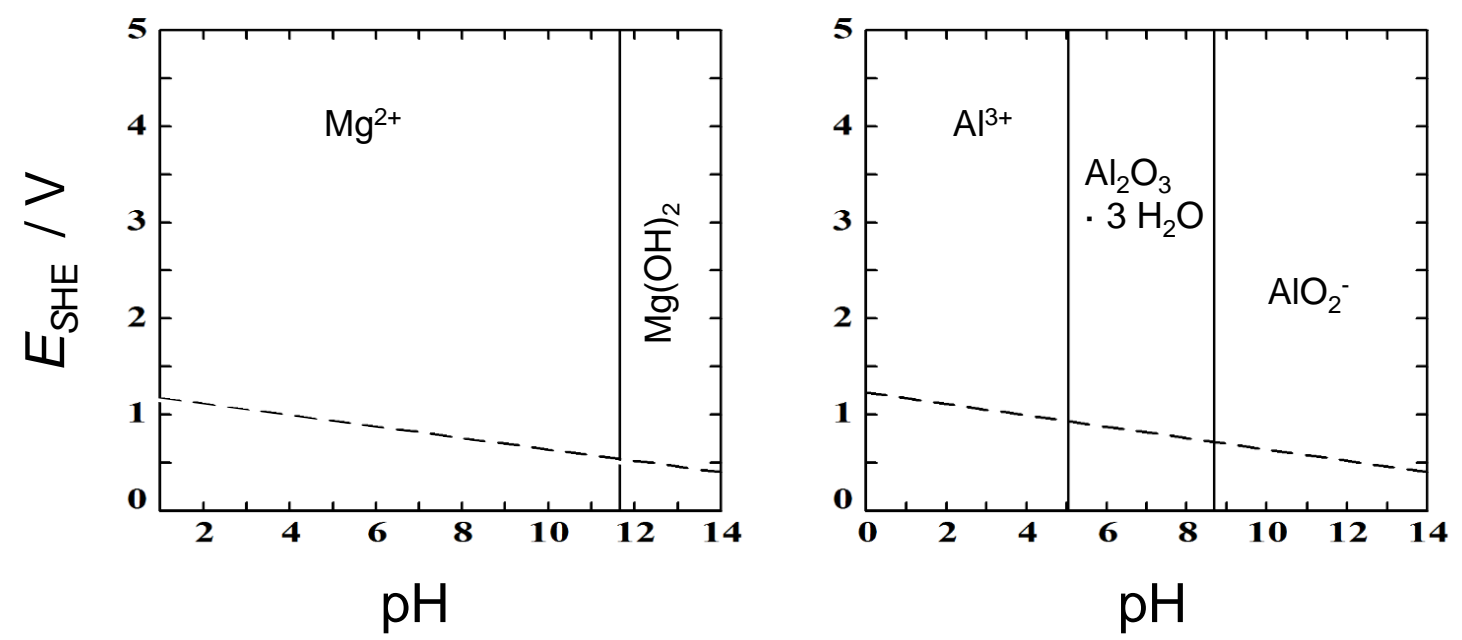

Figure 10. Pourbaix diagrams of magnesium (left) and aluminium (right) according to [32] drawn with the MEDUSA software [33], dashed lines mark the hydrolysis of water, potential related to the standard hydrogen electrode (SHE). 
Based on the model just proposed, the influence of the investigated electrolyte constituents on the passivation behaviour of Mg-AZ31, depicted in Figure 8, can be interpreted and categorised as follows:

- physiochemical passivation: adsorption of glycerol molecules on the substrate surface

$$
\mathrm{C}_{3} \mathrm{H}_{5}(\mathrm{OH})_{3(\mathrm{aq})} \rightarrow \mathrm{C}_{3} \mathrm{H}_{5}(\mathrm{OH})_{3(\mathrm{ads})}
$$

- chemical passivation: buffering of the protons released according to Equations (5) and (6) by phosphate ions

$$
\begin{aligned}
\mathrm{PO}_{4}^{3-}+\mathrm{H}^{+} & \rightarrow \mathrm{HPO}_{4}^{2-} \\
\mathrm{HPO}_{4}^{2-}+\mathrm{H}^{+} & \rightarrow \mathrm{H}_{2} \mathrm{PO}_{4}^{1-}
\end{aligned}
$$

- electrochemical passivation: passive layer enforcement by reaction of phosphate and fluoride with magnesium to stable, electrical isolating compounds

$$
\begin{aligned}
\mathrm{Mg} & \rightarrow \mathrm{Mg}^{2+}+2 \mathrm{e}^{-} \\
3 \mathrm{Mg}^{2+}+2 \mathrm{PO}_{4}^{3-} & \rightarrow \mathrm{Mg}_{3}\left(\mathrm{PO}_{4}\right)_{2} \\
\mathrm{Mg}^{2+}+2 \mathrm{~F}^{-} & \rightarrow \mathrm{MgF}_{2}
\end{aligned}
$$

According to the species distribution diagram of phosphates at $\mathrm{pH}$ of 13 , both $\mathrm{PO}_{4}^{3-}$ and $\mathrm{HPO}_{4}^{2-}$ exist, approximately in a ratio of 4:1. So, for the electrochemical passivation, several reactions with formation of various Mg-P-O-H compounds are conceivable.

Based on these assumptions, the effect sizes and the statistical significance summarised in Figure 9 can be explained as follows. Glycerol molecules adsorb at the substrate/electrolyte interface and limit the possible charge-carrier flow. So, the $\sigma_{1}$-value is lowered. However, this effect is rather weak and becomes statistically significant only with increased concentration and degree of coverage. Hence, $\mathrm{C}_{3} \mathrm{H}_{5}(\mathrm{OH})_{3}$ is just bonded physiochemically to the substrate, the gas formation between $t_{3}$ and $t_{4}\left(\sigma_{2}\right)$ leads to elevated statistical derivations and to a lowered significance. The presence of phosphate within the electrolyte could lead to the formation of various insoluble compounds within the passive film.

In order to ensure that this reaction layer does not rip open or flake off and can therefore have a good electrical insulation effect, the unit cell volumes of the reaction product and the substrate metal must be in a favourable ratio. In the case of atmospheric oxidation, this is described by the Pilling-Bedworth ratio (PBR). Song extended this concept in the context of PEO to reaction layers formed in aqueous media and introduced the term product-metal ratio (PMR). For both terms, values below 1 lead to rip open, values above 2 lead to the layer flaking off [34,35].

Table 4 summarises the PMRs of magnesium hydroxide which should usually be formed on magnesium in alkaline media, some Mg-P compounds which could be the result in presence of phosphate within the electrolyte and magnesium fluoride.

Table 4. PMRs and the material data necessary for their calculation for selected magnesium compounds.

\begin{tabular}{llllll}
\hline Substance & $x$ & $\mathbf{M} / \mathbf{g} \cdot \mathbf{m o l}^{\mathbf{- 1}}$ & $\boldsymbol{\rho} \mathbf{g} \cdot \mathbf{c m}$ & & PMR \\
\hline $\mathrm{Mg}(\mathrm{OH})_{2}$ & 1 & 58.32 & 2.37 & {$[36]$} & 1.76 \\
$\mathrm{Mg}_{2} \mathrm{P}_{2} \mathrm{O}_{7}$ & 2 & 222.55 & 2.56 & {$[36]$} & 3.11 \\
$\mathrm{Mg}_{3}\left(\mathrm{PO}_{4}\right)_{2}$ & 3 & 262.85 & 3.06 & {$[37]$} & 2.05 \\
$\mathrm{Mg}_{3} \mathrm{P}_{2}$ & 3 & 134.86 & 2.06 & {$[36]$} & 1.56 \\
$\mathrm{MgF}_{2}$ & 1 & 62.30 & 3.15 & {$[36]$} & 1.42 \\
\hline
\end{tabular}


The PMR values are calculated with $M_{\mathrm{Mg}}=24.3 \mathrm{~g} / \mathrm{mol}$ and $\rho_{\mathrm{Mg}}=1.73 \mathrm{~g} / \mathrm{cm}^{3}$ according to the following equation:

$$
\operatorname{PMR}=\frac{M_{\mathrm{p}} \cdot \rho_{\mathrm{Mg}}}{x \cdot M_{\mathrm{Mg}} \cdot \rho_{\mathrm{p}}}
$$

Here, the index $\mathrm{p}$ stands for the formed reaction product and $x$ for the number of magnesium atoms contained therein. Most of the Mg-P compounds listed have an unfavourable PMR $>2$. This could explain that, at low phosphate concentration, passive film reinforcement takes place ( $\sigma_{1}$ decreased), while higher phosphate fractions in the electrolyte lead to a poorer insulating reaction layer ( $\sigma_{1}$ increases). However, a decrease in $\sigma_{2}$ can be observed for both concentration levels. This can be interpreted as chemical passivation or buffering according to Equations (8) and (9).

The use of fluoride-containing electrolytes led to a sharp reduction in the two passivation values, as well as to a complete disappearance of the characteristic current-density peaks. The latter were clearly assigned to the properties of $\mathrm{Mg}(\mathrm{OH})_{2}$ in the model presented here. This suggests that the $\mathrm{Mg}-\mathrm{F}$ compounds (presumably $\mathrm{MgF}_{2}$ ) produced have largely displaced magnesium hydroxide from the passive film or are formed as a result of the local $\mathrm{pH}$ lowering. This is in accordance with the work of Duck, who generated a PEO coating on Mg-AZ91 within a KF-containing electrolyte and detected elevated amounts of $\mathrm{MgF}$ compounds directly in the barrier layer (thickness of a few $\mathrm{nm}$ ) close to the substrate (EDX analysis on TEM lamella) [38]. Magnesium fluoride is chemically very stable and has a favourable PMR toward magnesium. Thus, suppressing the current-density peaks described in this work could be the mode of action of fluoride compounds in commercial electrolyte for the PEO of magnesium. Parasitic reactions during polarity reversal would be suppressed and thus an improved layer adhesion would be achieved.

\section{Conclusion}

- A new method for the quantification of the passivation behaviour of substrate electrolyte combinations has been established. This procedure requires only low volumes and is suitable for the further development of PEO processes.

- A depassivation effect that occurs on formed $\mathrm{Mg}$ passive films has been described, which represents a significant difference to the passivation of aluminium materials.

i An electrochemical model was developed to describe this mechanism.

ii The model was used to explain the occurrence of insufficient layer adhesion in the PEO of magnesium and fluoride-free electrolytes.

- The following categorisation of the passivation mechanisms relevant for the PEO has been proposed:

i physiochemical passivation by adsorption of organic compounds at the substrate/electrolyte interface

ii chemical passivation by buffering of anodic formed protons

iii electrochemical passivation by formation of chemically stable, electrically insulating, insoluble reaction products within the passive layer

- A new theory about the mode of action of fluoride compounds in PEO electrolytes for magnesium has been presented.

This finding can serve as a basis to avoid toxic fluorides in the future, and to develop nontoxic, REACH-compliant electrolytes for the PEO of magnesium. First of all, however, it is necessary to validate in further studies using analytical methods whether the assumptions made in this study regarding passive film composition are correct. One approach could be EDX measurements on TEM lamella of the produced passive layers. Further more, it should be clarified by ICP analyses of the electrolyte if anodic metal dissolution of magnesium really takes place during the current-density peaks. 
In the next step, process data analysis of PEO experiments has to clarify whether the mechanisms described for the pre-breakdown phase really come into play during the plasma electrolytic oxidation. Afterwards adjusted pulse patterns could be used to minimize the number of critical potential passes.

Author Contributions: F.S. and M.S. conceived and designed the experiments, F.S. performed the experiments, analysed the data, and wrote the paper. T.M. and T.L. directed the research and contributed to the discussions and interpretations of the results. All authors have read and agreed to the published version of the manuscript.

Funding: This research was funded by the German Research Foundation (Deutsche Forschungsgemeinschaft/DFG) Grant No. LA-1274/46-1.

Acknowledgments: The work of Morgan Uland and Martin Kunze is gratefully acknowledged.

Conflicts of Interest: The authors declare no conflict of interest.

\section{References}

1. Yerokhin, A.L.; Nie, X.; Leyland, A.; Matthews, A.; Dowey, S.J. Plasma electrolysis for surface engineering. Surf. Coat. Technol. 1999, 122, 73-93. [CrossRef]

2. Wielage, B.; Alisch, G.; Lampke, T.; Nickel, D. Anodizing-a key for surface treatment of aluminium. Key Eng. Mater. 2008, 384, 263-281. [CrossRef]

3. Yerokhin, A.L. Discharge characterization in plasma electrolytic oxidation of aluminium. J. Phys. D Appl. Phys. 2003, 36, 2110-2120. [CrossRef]

4. Kurze, P. Production, Characterization and Application of $\mathrm{Al}_{2} \mathrm{O}_{3}$ Layers, Especially on Aluminium and Iron Materials. Ph.D. Thesis, Tu Chemnitz, Chemnitz, Germany, 1982. (In German).

5. Kurze, P.; Krysmann, W.; Marx, G. About anodic oxidation of aluminum under spark discharge ANOF in aqueous electrolytes. Wiss. Z. d. Techn. Hochsch. Karl-Marx-Stadt 1982, 24, 665-671. (In German)

6. Snizhko, L.O.; Yerokhin, A.L.; Gurevina, N.L.; Misnyankin, D.O.; Pilkington, A.; Leyland, A.; Matthews, A. A model for galvanostatic anodising of al in alkaline solutions. Electrochim. Acta 2005, 50, 5458-5464. [CrossRef]

7. Snizhko, L.O.; Yerokhin, A.; Gurevina, N.L.; Misnyankin, D.O.; Ciba, A.V.; Matthews, A. Voltastatic studies of magnesium anodising in alkaline solutions. Surf. Coat. Technol. 2010, 205, 1527-1531. [CrossRef]

8. Sieber, M.; Simchen, F.; Scharf, I.; Lampke, T. Formation of a spinel coating on AZ31 magnesium alloy by plasma electrolytic oxidation. J. Mater. Eng. Perform. 2016, 25, 1157-1162. [CrossRef]

9. Wu, D.; Liu, X.; Lu, K.; Zhang, Y.; Wang, H. Influence of $\mathrm{C} 3 \mathrm{H} 8 \mathrm{O} 3$ in the electrolyte on characteristics and corrosion resistance of the microarc oxidation coatings formed on AZ91D magnesium alloy surface. Appl. Surf. Sci. 2009, 255, 7115-7120. [CrossRef]

10. Qiu, Z.; Zhang, Y.; Li, Y.; Sun, J.; Wang, R.; Wu, X. Glycerol as a leveler on ZK60 magnesium alloys during plasma electrolytic oxidation. RSC Adv. 2015, 5, 63738-63744. [CrossRef]

11. Simchen, F.; Rymer, L.M.; Sieber, M.; Lampke, T. Composition of highly concentrated silicate electrolytes and ultrasound influencing the plasma electrolytic oxidation of magnesium. IOP Conf. Ser. Mat. Sci. Eng. 2017, 181, 012040. [CrossRef]

12. Arrabal, R.; Matykina, E.; Viejo, F.; Skeldon, P.; Thompson, G.E. Corrosion resistance of WE43 and AZ91D magnesium alloys with phosphate peo coatings. Corros. Sci. 2008, 50, 1744-1752. [CrossRef]

13. Schmelling, E.L.; Röschenbleck, B.; Weidemann, M.H. Method for the Production of Corrosion and Wear Resistant Protective Layers on Magnesium and Magnesium Alloys (German). EP 0333048 A1, 20 September 1989.

14. Yun, G.Y.; You, J.I.; You, J.Y.; Yun,J.G.; Kim, J.H.; Park, C.H.; Kim, D.H.; Lee, M.K. Composition for Plasma Electrolytic Oxidation (PEO) Treatment of Magnesium Alloy Products. US P 8337689 B2, 25 December 2012.

15. Blawert, C.; Dietzel, W.; Ghali, E.; Song, G. Anodizing treatments for magnesium alloys and their effect on corrosion resistance in various environments: Dow17 hae. Adv. Eng. Mat. 2006, 8, 511-533. [CrossRef]

16. Darband, G.; Aliofkhazraei, M.; Hamghalam, P.; Valizade, N. Plasma electrolytic oxidation of magnesium and its alloys: Mechanism, properties and applications. J. Magnes. Alloy. 2017, 5, 74-132. [CrossRef]

17. Wang, L.; Chen, L.; Yan, Z.; Wang, H.; Peng, J. Effect of potassium fluoride on structure and corrosion resistance of plasma electrolytic oxidation films formed on az31 magnesium alloy. J. Alloy. Compd. 2009, 480, 469-474. [CrossRef] 
18. Liang, J.; Guo, B.; Tian, J.; Liu, H.; Zhou, J.; Xu, T. Effect of potassium fluoride in electrolytic solution on the structure and properties of microarc oxidation coatings on magnesium alloy. Appl. Surf. Sci. 2005, 252, 345-351. [CrossRef]

19. Wierzbicka, E.; Pillado, B.; Mohedano, M.; Arrabal, R.; Matykina, E. Calcium Doped Flash-PEO Coatings for Corrosion Protection of Mg Alloy. Metals 2020, 10, 916. [CrossRef]

20. Kazanski, B.; Kossenko, A.; Zinigrad, M.; Lugovskoy, A. Fluoride ions as modifiers of the oxide layer produced by plasma electrolytic oxidation on AZ91D magnesium alloy. Appl. Surf. Sci. 2013, 287, 461-466. [CrossRef]

21. Moon, S.; Kwon, D. Anodic oxide films formed on AZ31 magnesium alloy by plasma electrolytic oxidation method in electrolytes containing various naf concentrations. J. Korean Inst. surf. Eng. 2016, 49, $225-230$. [CrossRef]

22. Liang, J.; Srinivasan, P.B.; Blawert, C.; Störmer, M.; Dietzel, W. Electrochemical corrosion behaviour of plasma electrolytic oxidation coatings on AM50 magnesium alloy formed in silicate and phosphate based electrolytes. Electrochim. Acta 2009, 54, 842-3850. [CrossRef]

23. Lu, X.; Blawert, C.; Scharnagl, N.; Kainer, K.U. Influence of incorporating $\mathrm{Si}_{3} \mathrm{~N}_{4}$ particles into the oxide layer produced by plasma electrolytic oxidation on AM50 Mg alloy on coating morphology and corrosion properties. J. Magnes. Alloy. 2013, 1, 267-274. [CrossRef]

24. Ma, X.; Blawert, C.; Höche, D.; Zheludkevich, M.L.; Kainer, K.U. Investigation of electrode distance impact on PEO coating formation assisted by simulation. Appl. Surf. Sci. 2016, 388, 304-312. [CrossRef]

25. Sieber, M.; Mehner, T.; Dietrich, D.; Alisch, G.; Nickel, D.; Meyer, D.; Scharf, I.; Lampke, T. Wear-resistant coatings on aluminium produced by plasma anodising-A correlation of wear properties, microstructure, phase composition and distribution. Surf. Coat. Technol. 2014, 240, 96-102. [CrossRef]

26. Sieber, M.; Simchen, F.; Morgenstern, R.; Scharf, I.; Lampke, T. Plasma electrolytic oxidation of high-strength aluminium alloys—substrate effect on wear and corrosion performance. Metals 2018, 8, 356. [CrossRef]

27. Song, G.; Atrens, A.; Stjohn, D.; Nairn, J.; Li, Y. The electrochemical corrosion of pure magnesium in $1 \mathrm{~N}$ NaCl. Corros. Sci. 1997, 35, 855-875. [CrossRef]

28. Bender, S.; Goellner, J.; Heyn, A.; Schmigalla, S. A new theory for the negative difference effect in magnesium corrosion. Mater. Corros. 2011, 63, 707-712. [CrossRef]

29. Rossrucker, L.; Samaniego, A.; Grote, J.P.; Mingers, A.M.; Laska, C.A.; Birbilis, N.; Frankel, G.S.; Mayrhofer, K.J.J. The $\mathrm{pH}$ Dependence of Magnesium Dissolution and Hydrogen Evolution during Anodic Polarization. J. Electrochem. Soc. 2015, 162, C333-C339. [CrossRef]

30. Simchen, F.; Sieber, M.; Lampke, T. Electrolyte influence on ignition of plasma electrolytic oxidation processes on light metals. Surf. Coat. Technol. 2017, 315, 205-213. [CrossRef]

31. Ono, S.; Moronuki, S.; Mori, Y.; Koshi, A.; Liao, J.; Asoh, H. Effect of Electrolyte Concentration on the Structure and Corrosion Resistance of Anodic Films Formed on Magnesium through Plasma Electrolytic Oxidation. Electrochim. Acta 2017, 240, 415-426. [CrossRef]

32. Pourbaix, M. Atlas of electrochemical equlibria in aquesouse solutions. NACE Int. Cebelcor 1974, 144 ff, $174 \mathrm{ff}$.

33. Puigdomenech, I. Medusa software: Make Equilibrium Diagrams Using Sophisticated Algorithms: Royal Institute of Technology; Stockholm, Sweden. 2010. Available online: https://www.kth.se/che/medusa (accessed on 16 September 2020).

34. Pilling, N.; Bedworth, R.J. The oxidation of metals at high temperatures. Inst. Met. 1923, $29,529$.

35. Song, L.; Song, Y.; Shan, D.;Zhu, G.; Han, E. Product/metal ratio (PMR): A novel criterion for the evaluation of electrolytes on micro-arc oxidation (MAO) of Mg and its alloys. Sci. China Technol. Sci. 2011, 54, $2795-2801$. [CrossRef]

36. Perry, D.L. Handbook of Inorganic Compounds, 2nd ed.; CRC Press: Boca Raton, FL, USA, 2011; p. 247 ff.

37. $\mathrm{Mg} 3 \mathrm{P} 2 \mathrm{O} 8$ (Mg3[PO4]2 m) Crystal Structure. Springer Materials. Available online: https://materials. springer.com/isp/crystallographic/docs/sd_1904740 (accessed on 16 September 2020).

38. Hwang, D.Y.; Kim, Y.M.; Shin, D.H. Corrosion resistance of plasma-anodized AZ91 Mg alloy in the electrolyte with/without potassium fluoride. Mat. Trans. 2009, 50, 671-678.

(C) 2020 by the authors. Licensee MDPI, Basel, Switzerland. This article is an open access article distributed under the terms and conditions of the Creative Commons Attribution (CC BY) license (http:/ / creativecommons.org/licenses/by/4.0/). 